\title{
Perencanaan Sistem Kelistrikan PLTMH Banjar Dinas Mekar Sari
}

\author{
I P. E. April Yanto ${ }^{1}$, I. A. D. Giriantari ${ }^{2}$, W. G. Ariastina ${ }^{3}$ \\ [Submission: 17-12-2020, Accepted:18-01-2021]
}

\begin{abstract}
This paper introduces a redesign of Micro Hydro Power Plant (MHPP) in Banjar Dinas Mekar Sari, Panji Village, District of Sukasada, Buleleng Regency, Bali. The MHPP has been operated since 1980 by utilizing waterflow of Tukad Pasut River. Early investigation indicated that there is a reduced production capacity of the MHPP due to lack of maintenance. In addition, the initial design of the MHPP has not adopted the advanced power control systems, resulting in inefficient power production. The introduced design of the new MHPP utilizes a crossflow turbine to accommodate a waterflow rate of $1,32 \mathrm{~m}^{3} / \mathrm{s}$ and with an effective head of $16 \mathrm{~m}$. The turbine mechanical energy is coupled to a generator by means of a belt coupling system, with a belt length of $3099 \mathrm{~mm}$. The pulley diameter is $750 \mathrm{~mm}$ for the turbine side, and it is $149 \mathrm{~mm}$ for the generator side. The generator capacity is 185 $\mathrm{kVA}, 50 \mathrm{~Hz}, 230 / 400 \mathrm{~V}, 1500 \mathrm{rpm}$, and with an efficiency of $94 \%$. The Electronic Load Controller has a capacity of $180 \mathrm{~kW}$, with 6 ballast loads of $30 \mathrm{~kW}$. The connection from the generator to the transformer uses the NYFGbY underground cable of $4 \times 95 \mathrm{~mm}^{2}$, with a length of $69 \mathrm{~m}$. The transformer is a step-up and step-down type with a capacity of $250 \mathrm{kVA}$.
\end{abstract}

Keywords: MHPP, Renewable Energy, Electrical Systems.

Intisari - Artikel ini mengemukakan tentang desain ulang Pembangkit Listrik Tenaga Mikrohidro (PLTMH) di Banjar Dinas Mekar Sari, Desa Panji, Kecamatan Sukasada, Kabupaten Buleleng, Bali. PLTMH tersebut telah beroperasi sejak tahun 1980, dengan memanfaatkan aliran air Sungai Tukad Pasut. Investigasi awal menunjukkan adanya penurunan kapasitas produksi PLTMH karena kurangnya perawatan. Selain itu, desain awal PLTMH tersebut belum mengadopsi sistem kontrol yang modern, sehingga mengakibatkan produksi listrik yang tidak efisien. Rancangan baru untuk PLTMH di Banjar Dinas Mekar Sari menggunakan turbin crossflow untuk mengakomodasi laju aliran air $1,32 \mathrm{~m}^{3} /$ detik dan dengan tinggi head efektif $16 \mathrm{~m}$. Energi mekanik turbin dikopel ke generator melalui sistem kopel belt dengan panjang sabuk $3099 \mathrm{~mm}$. Diameter pulley adalah $750 \mathrm{~mm}$ untuk sisi turbin, dan $149 \mathrm{~mm}$ untuk sisi generator. Kapasitas generator adalah 185 kVA, 50 $\mathrm{Hz}, 230 / 400 \mathrm{~V}, 1500 \mathrm{rpm}$, dan dengan efisiensi 94\%. Electronic Load Controller memiliki kapasitas $180 \mathrm{~kW}$, dengan 6 ballast load $30 \mathrm{~kW}$. Sambungan dari generator ke transformator menggunakan kabel bawah tanah NYFGbY $4 \times 95 \mathrm{~mm}^{2}$, dengan panjang $69 \mathrm{~m}$. Transformator berjenis step-up/step-down dengan kapasitas 250 kVA.

${ }^{1}$ Mahasiswa, Program Studi Teknik Elektro Fakultas Teknik Universitas Udayana, Br. Dalem, Pejaten, Kediri, Tabanan (telp: 085739024292; e-mail: putu.eka486@gmail.com)

2, 3 Dosen, Program Studi Teknik Elektro Fakultas Teknik Universitas Udayana, Jln. Jalan Kampus Bukit Jimbaran 80361 INDONESIA (telp: 0361-703315; fax: 0361-4321; e-mail: dayu.giriantari@unud.ac.id ${ }^{2}$, w.ariastina@unud.ac.id ${ }^{3}$ )

\section{Kata Kunci : PLTMH, Energi terbarukan, Sistem Kelistrikan}

\section{Pendahuluan}

Indonesia merupakan negara yang memiliki sumber daya alam yang melimpah, termasuk juga sumber energi terbarukan. Potensi sumber energi terbarukan di Indonesia diantaranya adalah energi matahari, energi air, energi angin, biomassa, panas bumi, dan pasang surut air laut [1]. Pembangkit Listrik Tenaga Mikrohidro (PLTMH) adalah salah satu pembangkit listrik yang memanfaatkan energi terbarukan yaitu energi air. Potensi energi mini-mikro hidro berjumlah 19.385 MW di Indonesia. Pulau Bali memiliki potensi sebesar $30 \mathrm{MW}$ [2].

PLTMH Jatiluwih adalah salah satu pembangkit listrik yang telah beroperasi di Bali. PLTMH Jatiluwih dibangun atas kerjasama Pemerintah Kota Toyama Jepang, Pemerintah Kabupaten Tabanan, dan Universitas Udayana [3]. Selain itu, terdapat pula PLTMH di aliran sungai Tiying Tali, Buleleng yang perlu direvitalisasi agar dapat berfungsi dengan baik [4][5].

PLTMH lainnya yang terdapat di Bali adalah PLTMH yang dikelola oleh masyarakat Banjar Dinas Mekar Sari, Desa Panji, Kecamatan Sukasada, Kabupaten Buleleng. PLTMH tersebut memanfaatkan aliran Sungai Tukad Pasut sebagai PLTMH sejak tahun 1980. Pada tahun 2019, PLTMH Banjar Dinas Mekar Sari mengalami penurunan unjuk kerja. Generator PLTMH yang berkapasitas $10 \mathrm{~kW}$ hanya dapat menghasilkan daya sebesar $200 \mathrm{~W}$ atau $2 \%$ dari kapasitasnya. Penurunan unjuk kerja ini disebabkan karena tidak adanya pemeliharaan secara berkala. Berdasarkan keterbatasan tersebut maka perlu dilakukan perencanaan kembali sistem kelistrikan PLTMH Banjar Dinas Mekar Sari agar dapat beroperasi sesuai dengan potensi yang dimiliki. Sistem kelistrikan dirancang beroperasi secara on-grid dan komponen yang digunakan disesuaikan dengan komponen yang tersedia secara komersial.

\section{KAJIAN PUSTAKA}

PLTMH adalah pembangkit listrik skala kecil yang memanfaatkan tenaga air sebagai tenaga penggerak [6]. PLTMH pada dasarnya memanfaatkan energi potensial jatuhan air (head) dan jumlah debit air. Pembangkit listrik tenaga air dengan kapasitas sampai $200 \mathrm{~kW}$ digolongkan kedalam PLTMH [7]. Komponen PLTMH terdiri dari komponen sipil, komponen mekanikal, dan komponen elektrikal yang dapat diuraikan sebagai berikut [8]:

1 Bendungan Pengalih (intake), sebagai pengalih air dari sisi sungai menuju ke bak pengendapan.

2 Bak Pengendap (settling basin), tempat untuk mengendapkan sedimentasi yang ikut terbawa aliran air.

I P. E. April Yanto: Perencanaan Sistem Kelistrikan Pembangkit ... 
3 Saluran Pembawa (headrace), digunakan sebagai saluran untuk membawa air mengikuti kontur tanah.

4 Bak penenang (forebay), digunakan untuk meredam turbulensi air.

5 Pipa Pesat (penstock), digunakan untuk menjatuhkan air sehingga dapat memutar turbin.

6 Turbin, berfungsi untuk mengubah energi potensial air menjadi energi mekanik.

7 Pipa Hisap, (draft tube), digunakan untuk menghisap air dan mengembalikan tekanan air.

8 Generator, digunakan untuk mengubah energi mekanis menjadi energi listrik.

9 Sistem kontrol, berfungsi untuk menjaga output generator agar tetap stabil dan sebagai sistem pengaman.

\section{A. Generator}

Generator merupakan komponen yang dapat mengubah energi mekanik menjadi energi listrik. Kapasitas generator yang digunakan PLTMH ditentukan berdasarkan potensi daya input pada sisi generator. Skema potensi daya PLTMH ditunjukkan pada Gambar 1.

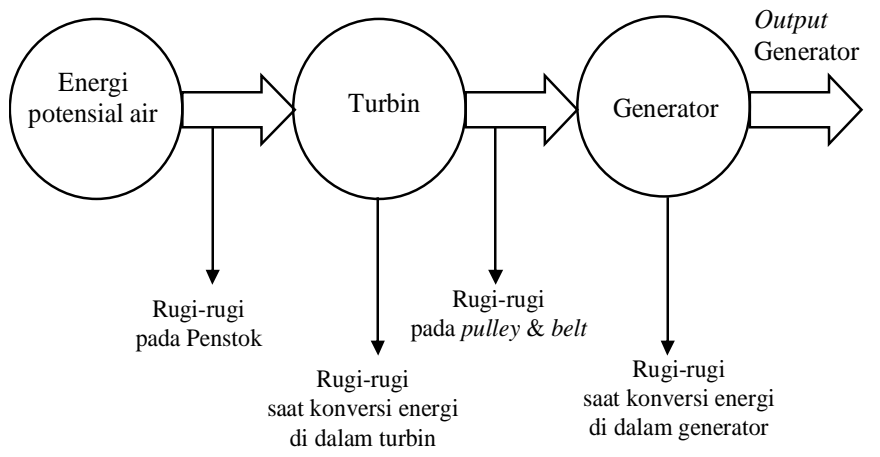

Gambar 1: Skema Potensi Daya PLTMH

Potensi daya luaran PLTMH dapat dihitung dengan menggunakan Persamaan (1), (2), dan (3) [9]:

$$
\begin{aligned}
& \mathrm{P}_{\text {Teoritis }}=9,81 \times \rho \times \mathrm{Q} \times \mathrm{H}_{\mathrm{eff}} \\
& \mathrm{P}_{\text {Output Turbin }}=9,81 \times \rho \times \eta_{\mathrm{t}} \times \mathrm{Q} \times \mathrm{H}_{\mathrm{eff}} \\
& \mathrm{P}_{\text {Output Generator }}=9,81 \times \rho \times \eta_{\mathrm{g}} \times \eta \mathrm{t} \times \mathrm{Q} \times \\
& \text { dengan, } \\
& \mathrm{P}=\text { Daya yang dihasilkan }(\mathrm{kW}) \\
& \eta_{\mathrm{t}}=\text { Efisiensi turbin }(\%) \\
& \eta_{\mathrm{g}}=\text { Efisiensi generator }(\%) \\
& \rho=\text { Massa jenis air }\left(\mathrm{kg} / \mathrm{m}^{3}\right) \\
& \mathrm{Q}=\text { Debit air }\left(\mathrm{m}^{3} / \mathrm{s}\right) \\
& \mathrm{H}_{\mathrm{eff}}=\text { Tinggi jatuh efektif }(\mathrm{m})
\end{aligned}
$$$$
\mathrm{P}_{\text {Output Generator }}=9,81 \times \rho \times \eta_{\mathrm{g}} \times \eta \mathrm{t} \times \mathrm{Q} \times \mathrm{H}_{\mathrm{eff}}
$$

\section{B. Transmisi Mekanik}

Transmisi mekanik digunakan untuk mentransmisikan daya dari turbin ke generator. Transmisi mekanik dapat dilakukan secara langsung dengan kopel apabila putaran turbin sama dengan putaran generator. Jika terdapat perbedaan putaran antara turbin dengan generator maka digunakan sistem transmisi tak langsung yaitu pulley dan belt [10]. Perbandingan diameter pulley dapat dihitung dengan menggunakan Persamaan (4) [11]:

$$
\frac{n 1}{n 2}=\frac{d 2}{d 1}
$$

dengan,

$\mathrm{n}_{1}=$ Putaran poros pertama (rpm)

$\mathrm{n}_{2}=$ Putaran poros kedua $(\mathrm{rpm})$

$\mathrm{d}_{1}=$ Diameter pulley penggerak $(\mathrm{mm})$

$\mathrm{d}_{2}=$ Diameter pulley yang digerakan $(\mathrm{mm})$

Belt adalah komponen yang digunakan untuk menghubungkan kedua buah pulley sehingga turbin dapat menggerakkan generator. Panjang belt dapat dihitung dengan menggunakan Persamaan (5) [11]:

$$
\begin{aligned}
& \mathrm{L}=2 \mathrm{C}+\frac{\pi}{2}\left(\mathrm{~d}_{\mathrm{p}}+\mathrm{D}_{\mathrm{p}}\right)+\frac{1}{4 C}\left(\mathrm{~d}_{\mathrm{p}}+\mathrm{D}_{\mathrm{p}}\right) \\
& \text { dengan, } \\
& \mathrm{L}=\text { Panjang keliling sabuk }(\mathrm{mm}) \\
& \mathrm{C}=\text { Jarak antara poros }(\mathrm{mm}) \\
& \mathrm{dp}=\text { Diameter pulley yang digerakkan }(\mathrm{mm}) \\
& \mathrm{Dp}=\text { Diameter pulley penggerak }(\mathrm{mm})
\end{aligned}
$$

\section{Electronic Load Controller (ELC)}

ELC adalah suatu sistem kontrol pada PLTMH yang berfungsi untuk menjaga frekuensi PLTMH tetap stabil [12]. Prinsip kerja $E L C$ adalah dengan cara mengatur besar daya yang diserap agar bernilai sama dengan daya yang dihasilkan generator. ELC membagi arus PLTMH menuju beban konsumen dan ballast load, sehingga PLTMH akan tetap beroperasi pada keadaan nominal walaupun beban konsumen berubah-ubah. Skema prinsip kerja ELC ditunjukkan pada Gambar 2.

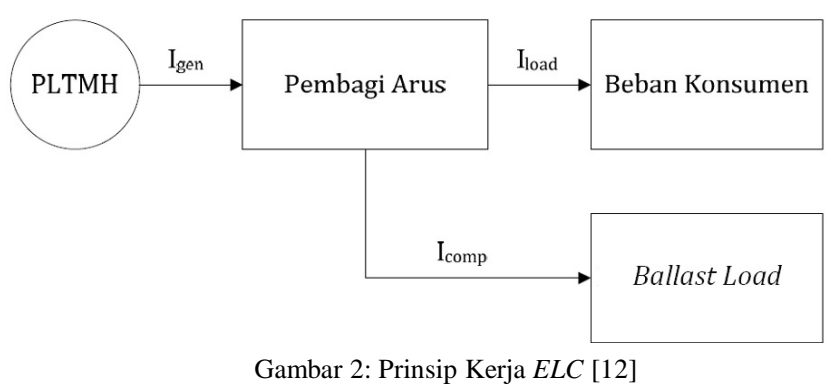

Metode yang dapat digunakan untuk mengatur jumlah daya yang disalurkan menuju ballast load adalah menggunakan beban kontinu dengan mengatur penyalaan sudut fasa pada penyulutan thyristor [13]. Diagram blok ELC dengan penyulutan thyristor ditunjukkan pada Gambar 3.

Tegangan sistem diturunkan dengan trafo step down, kemudian diteruskan ke rangkaian Zero Crossing Detector untuk diubah menjadi gelombang pulsa dan dikonversikan menjadi besaran tegangan DC yang sebanding dengan frekuensi sistem. Tegangan DC yang merupakan representasi dari frekuensi sistem, digunakan sebagai masukan mikroprosesor, sehingga apabila terjadi perubahan frekuensi sistem maka mikroprosesor akan menyulut thyristor dan ballast load sesuai dengan hasil ukur frekuensi error. Penyulutan thyristor dilakukan dengan mengatur sudut fasa (phase angle control) sampai frekuensi nominal tercapai [13]. 


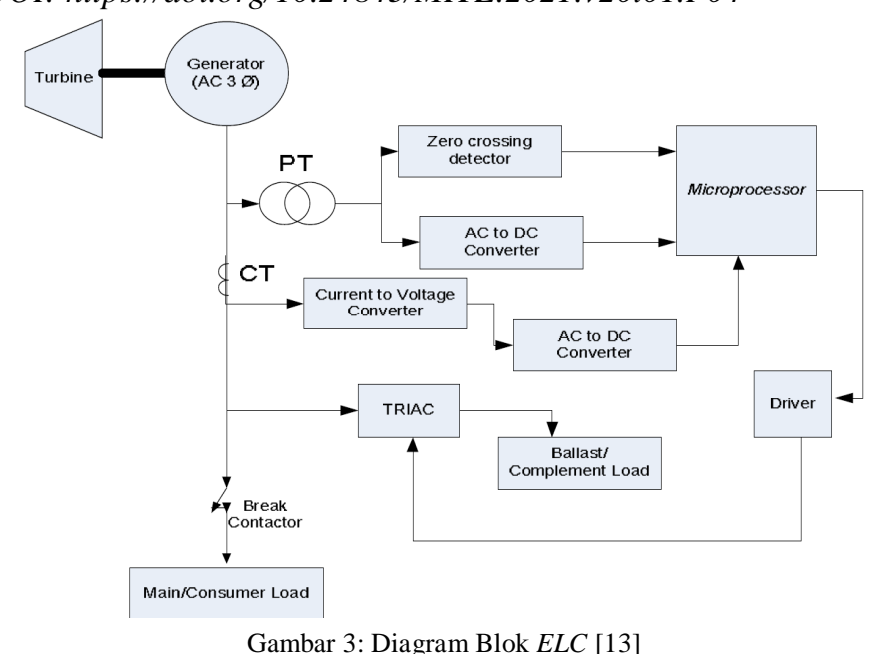

D. Pemakaian Sendiri

Energi listrik diperlukan PLTMH untuk kebutuhan operasional, sehingga jumlah beban yang akan digunakan PLTMH perlu diperhitungkan. Kebutuhan kelistrikan PLTMH meliputi penerangan dan beberapa kotak kontak. Perhitungan jumlah kotak kontak yang diperlukan berdasarkan pada jumlah peralatan dan besar daya dari peralatan tersebut. Sedangkan perhitungan jumlah titik lampu berdasarkan pada ukuran dan peruntukan ruangan yang akan digunakan. Jumlah titik lampu pada sebuah ruangan dapat dihitung dengan Persamaan (6) [14]:

$$
\begin{aligned}
& \mathrm{n}=\frac{E \times A}{\text { Өlampu } \times \mu \times \mathrm{d}} \\
& \text { dengan, } \\
& \mathrm{n}=\text { Jumlah titik lampu } \\
& \mathrm{E}=\text { Intensitas penerangan di bidang kerja (lux) } \\
& \mathrm{A}=\text { Luas ruangan }\left(\mathrm{m}^{2}\right) \\
& \Theta_{\text {lampu }}=\text { Intensitas cahaya lampu (lumen) } \\
& \mu=\text { Efisiensi penerangan } \\
& \mathrm{d}=\text { Faktor depresiasi }
\end{aligned}
$$

\section{E. Jaringan Tegangan Rendah}

Jaringan tegangan rendah memiliki tiga jenis konstruksi, salah satu diantaranya adalah Saluran Kabel Tanah Tegangan Rendah. Penggunaan konstruksi Saluran Kabel Tanah Tegangan Rendah harus mempertimbangkan jarak aman dengan instalasi lain. Jarak persilangan kabel minimal $20 \mathrm{~cm}$. Apabila jarak kurang dari itu, maka persilangan wajib dilindungi dengan plat beton atau pipa beton belah setebal 6 $\mathrm{cm}$, minimal $50 \mathrm{~cm}$ dari titik silang [15].

Pada konstruksi Saluran Kabel Tanah Tegangan Rendah, kabel ditanam sedalam $70 \mathrm{~cm}$ dan diberi pasir urug setebal 20 $\mathrm{cm}$ dengan lebar galian sekurang-kurangnya $40 \mathrm{~cm}$. Pada bagian atas pasir dipasang beton pengaman sebagai peringatan dengan tebal sekurang-kurangnya $6 \mathrm{~cm}$ dan pada bagian atas ditulis “Awas Kabel PLN Bertegangan” [15].

Jenis kabel yang digunakan pada jaringan ditentukan berdasarkan konstruksi jaringan yang digunakan dan besar arus yang disalurkan [16]. Besar nilai arus yang disalurkan dapat dihitung dengan Persamaan (7) [17].

$$
\begin{aligned}
& I_{\text {saluran }}=\frac{S}{\sqrt{3} \times V} \\
& \text { dengan, } \\
& \mathrm{I}=\text { Arus nominal (A) } \\
& \mathrm{S}=\text { Daya semu (VA) } \\
& \mathrm{V}=\text { Tegangan fasa-fasa }(\mathrm{V})
\end{aligned}
$$

Kemampuan hantar arus suatu penghantar ditentukan berdasarkan jenis dan luas penampang dari penghantar tersebut. Kemampuan hantar arus pada penghantar dapat dilihat melalui katalog spesifikasi penghantar yang digunakan.

\section{F. Pemilihan Transformator}

Pemilihan transformator daya pada pembangkit disesuaikan dengan kapasitas generator yang digunakan dan disarankan untuk menggunakan tipe pemasangan luar. Persentase pembebanan transformator agar terhindar dari overload adalah sebesar $80 \%$ dari kapasitasnya. Berdasarkan hal tersebut, maka kapasitas transformator dapat dihitung dengan Persamaan (8) [18].

$$
\begin{aligned}
& \mathrm{S}_{\text {trafo }}=\frac{S(k V A)}{0,8} \\
& \text { dengan, } \\
& \mathrm{S}_{\text {trafo }}=\text { Kapasitas transformator }(\mathrm{kVA}) \\
& \mathrm{S}_{(\mathrm{kVA})}=\text { Daya maksimum generator/beban }(\mathrm{kVA}) \\
& 0,8=\text { Konstanta/batas aman penentuan } \\
& \text { transformator }
\end{aligned}
$$

\section{METODE PENELITIAN}

Perencanaan sistem kelistrikan PLTMH di Banjar Dinas Mekar Sari, Desa Panji, Kecamatan Sukasada, Kabupaten Buleleng dirancang beroperasi secara on-grid. Penelitian diawali dengan melakukan observasi secara langsung ke PLTMH yang berlokasi di Banjar Dinas Mekar Sari untuk mengetahui kondisi geografis di lingkungan penelitian. Data rancangan turbin dengan debit sebesar $1,32 \mathrm{~m}^{3} / \mathrm{s}$ dan tinggi jatuh air efektif sebesar $16 \mathrm{~m}$, digunakan untuk mengetahui potensi daya pada sisi input generator.

Langkah selanjutnya dilakukan perhitungan potensi daya yang dapat dibangkitkan generator sehingga dapat ditentukan kapasitas generator yang akan digunakan serta daya output yang dihasilkan. Berdasarkan data rancangan turbin dan pemilihan generator maka dirancang ukuran pulley dan belt yang digunakan. Kapasitas ELC dan ballast load dihitung berdasarkan kapasitas generator. Konstruksi JTR dipilih berdasarkan pertimbangan kondisi jalur yang dilalui, sedangkan pemilihan kabel JTR dipilih berdasarkan arus yang disalurkan. Transformator dipilih berdasarkan kapasitas generator yang digunakan dengan mempertimbangkan faktor keamanan dari transformator. Komponen yang digunakan dalam perancangan diperoleh berdasarkan data komponen yang tersedia secara komersial dan mendekati hasil perhitungan. 


\section{IV.HASIL DAN PEMBAHASAN}

Desa Panji terletak di Kecamatan Sukasada, Kabupaten Buleleng, Bali. Secara geografis Desa Panji berbatasan dengan Desa Ambengan di sebelah timur, Desa Wanagiri di sebelah selatan, Desa Panji Anom di sebelah barat, dan Desa Bhakti Segara di sebelah utara. Desa Panji memiliki luas wilayah sebesar 1061 hektar. Desa Panji terdiri dari delapan banjar dinas yaitu: Mekar Sari, Kembang Sari, Babakan, Bangah, Kelod Kauh, Dangin Pura, Dauh Pura, dan Mandul. Penduduk Desa Panji berjumlah 8.537 jiwa dengan 2.262 KK. Mata pencaharian penduduk Desa Panji diantaranya adalah petani, pedagang, pekebun, pengrajin, pegawai pemerintah, dan swasta [19]. Letak Desa Panji ditunjukkan pada Gambar 4.

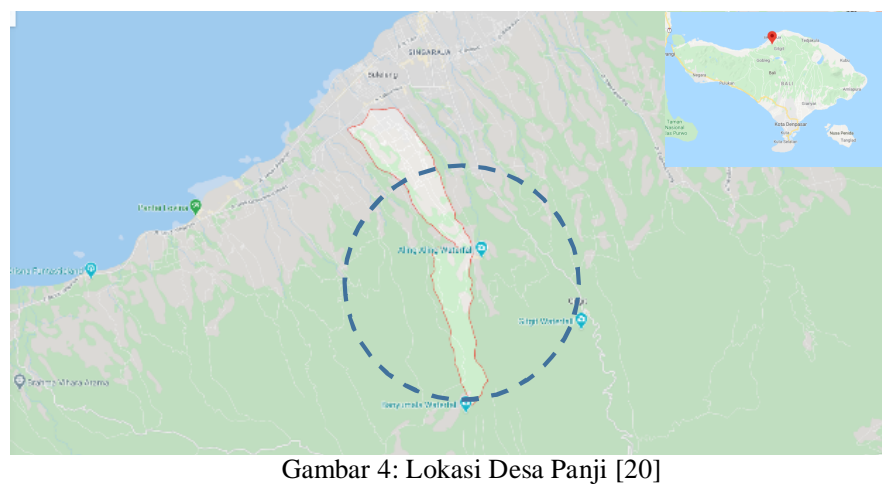

Wilayah Desa Panji merupakan dataran tinggi yang memiliki aliran sungai, baik sungai alami maupun saluran irigasi. Salah satu aliran sungai yang sudah dimanfaatkan oleh masyarakat untuk PLTMH adalah aliran Sungai Tukad Pasut yang melintasi Banjar Dinas Mekar Sari, Desa Panji.

PLTMH yang terletak di Banjar Dinas Mekar Sari telah ada dan beroperasi sejak tahun 1980. Kondisi PLTMH Banjar Dinas Mekar Sari sudah tidak dapat beroperasi secara maksimal. Generator yang dioperasikan pada PLTMH Banjar Dinas Mekar Sari berkapasitas $10 \mathrm{~kW}$. Namun, generator tersebut hanya menghasilkan daya sebesar $200 \mathrm{~W}$ atau $2 \%$ dari kapasitas Generator yang terpasang. Kondisi PLTMH Banjar Dinas Mekar Sari ditunjukkan pada Gambar 5. PLTMH Banjar Dinas Mekar Sari saat ini masih belum memiliki sistem kontrol. Listrik yang dihasilkan generator langsung digunakan untuk menyuplai beban lampu penerangan tanpa melalui sistem kontrol maupun sistem keamanan lainnya. Penurunan unjuk kerja dari PLTMH Banjar Dinas Mekar Sari dipengaruhi oleh tidak adanya pemeliharaan komponen secara berkala.

\section{A. Perancangan Turbin}

Jenis turbin dipilih berdasarkan pada hasil pengukuran debit air dan tinggi jatuh air efektif (head net). Debit air Sungai Tukad Pasut adalah sebesar $1,32 \mathrm{~m}^{3} / \mathrm{s}$ sedangkan tinggi jatuh air efektif adalah sebesar $16 \mathrm{~m}$, sehingga berdasarkan hal tersebut rancangan turbin PLTMH Banjar Dinas Mekar Sari menggunakan jenis turbin crossflow. Potensi daya PLTMH Banjar Dinas Mekar Sari secara teoritis adalah sebesar 207,187 kW. Dengan efisiensi turbin sebesar $89,5 \%$, maka daya output turbin adalah sebesar $185 \mathrm{~kW}$. Spesifikasi turbin crossflow PLTMH Banjar Dinas Mekar Sari berdasarkan hasil analisis ditunjukkan pada Tabel 1.

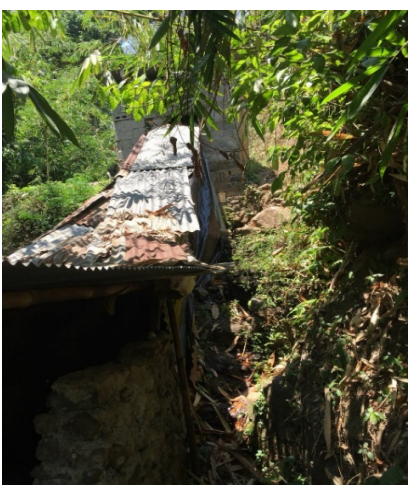

(a)

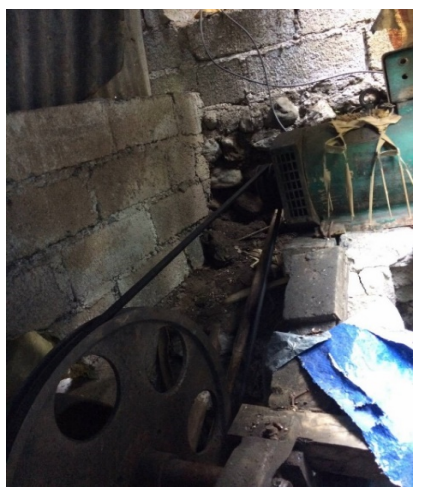

(b)
Gambar 5: Kondisi PLTMH Banjar Dinas Mekar Sari (a) Penstock dan Rumah Daya (b) Pulley, Belt, dan Generator TABEL I

SPESIFIKASI TURBIN CROSSFLOW PLTMH BANJAR DINAS MEKAR SARI [20]

\begin{tabular}{ccc}
\hline No & Indikator & Spesifikasi \\
\hline $\mathbf{1}$ & Daya Turbin & $185 \mathrm{~kW}$ \\
\hline $\mathbf{2}$ & Putaran Turbin & $298 \mathrm{rpm}$ \\
\hline $\mathbf{3}$ & Tinggi Jatuh Air & $16 \mathrm{~m}$ \\
\hline $\mathbf{4}$ & Debit aliran & $1,32 \mathrm{~m}^{3} / \mathrm{s}$ \\
\hline $\mathbf{5}$ & Posisi Poros & horizontal \\
\hline $\mathbf{6}$ & Efisiensi Turbin & $89,50 \%$ \\
\hline $\mathbf{7}$ & Sudut Serang & $16^{\circ}$ \\
\hline $\mathbf{8}$ & Torsi turbin & $5962,46 \mathrm{Nm}$ \\
\hline $\mathbf{9}$ & Diameter Luar Runner & $54 \mathrm{~cm}$ \\
\hline $\mathbf{1 0}$ & Diameter dalam Runner & $36 \mathrm{~cm}$ \\
\hline
\end{tabular}

\section{B. Pemilihan Generator}

Pemilihan kapasitas generator disesuaikan dengan potensi daya pada sisi input generator. Daya output rancangan turbin PLTMH Banjar Dinas Mekar Sari adalah sebesar 185 kW. Daya yang dihasilkan pada turbin kemudian mengalami rugirugi kembali pada transmisi mekanik. Efisien pada transmisi mekanik adalah sebesar 95\% [21], sehingga daya yang dapat dibangkitkan pada sisi input generator dapat dihitung dengan cara sebagai berikut:

$$
\begin{aligned}
\mathrm{P}_{\text {Input Generator }} & =\mathrm{P}_{\text {Output Turbin }} \times \eta \text { Transmisi } \\
& =185 \mathrm{~kW} \times 0,95 \\
& =175,75 \mathrm{~kW} \approx 176 \mathrm{~kW}
\end{aligned}
$$

Kapasitas generator yang digunakan berdasarkan hasil perhitungan adalah sebesar $176 \mathrm{kVA}$. Dari hasil survei, generator yang tersedia secara komersial dan mendekati hasil perhitungan adalah Generator Sinkron $185 \mathrm{kVA}, 50 \mathrm{~Hz}$, 230/400 V, $1500 \mathrm{rpm}$, dengan efisiensi generator sebesar 94\%.

Berdasarkan nilai efisiensi generator yang digunakan pada PLTMH Banjar Dinas Mekar Sari maka dapat dihitung daya output generator yaitu:

$$
\begin{aligned}
\mathrm{S}(\mathrm{kVA}) & =176 \mathrm{kVA} \times 94 \% \\
& =165,44 \mathrm{kVA}
\end{aligned}
$$

\section{Perencanaan Pulley dan Belt}

Rancangan turbin PLTMH Banjar Dinas Mekar Sari memiliki selisih kecepatan putaran dengan generator yang digunakan, sehingga pulley dan belt digunakan sebagai transmisi mekanik untuk mentransmisikan daya. Berdasarkan hasil analisis, kecepatan putaran turbin PLTMH Banjar Dinas Mekar Sari yang dirancang adalah sebesar $298 \mathrm{rpm}$ [20]. 
Sedangkan kecepatan putaran generator yang digunakan adalah sebesar $1500 \mathrm{rpm}$. Diameter pulley berbanding terbalik dengan kecepatan putar pulley. Berdasarkan data tersebut, didapatkan perbandingan diameter pulley yang digunakan sebagai berikut :

$$
\begin{aligned}
& \frac{n 1}{n 2}=\frac{d 2}{d 1} \\
& \frac{298}{1500}=\frac{d 2}{d 1}
\end{aligned}
$$

Berdasarkan perhitungan diatas, maka perbandingan antara diameter pulley turbin dengan pulley generator adalah 15 : 2,98. Pulley yang digunakan pada sisi turbin berdiameter 750 $\mathrm{mm}$, sedangkan pulley yang digunakan pada sisi generator berdiameter $149 \mathrm{~mm}$.

Panjang belt yang digunakan dapat dihitung dengan rumus sebagai berikut, dengan asumsi jarak antar poros sebesar 800 mm [11]. Asumsi jarak $800 \mathrm{~mm}$ digunakan agar ruang yang dibutuhkan untuk transmisi mekanis tidak luas.

$$
\begin{aligned}
& \mathrm{L}=2 \mathrm{C}+\frac{\pi}{2}\left(\mathrm{~d}_{\mathrm{p}}+\mathrm{D}_{\mathrm{p}}\right)+\frac{1}{4 C}\left(\mathrm{~d}_{\mathrm{p}}+\mathrm{D}_{\mathrm{p}}\right) \\
& \mathrm{L}=2 .(800)+\frac{3,14}{2}(149+750)+\frac{1}{4 .(800)}(149+750) \\
& \mathrm{L}=1600+1411,43+0,28 \\
& \mathrm{~L}=3011,71 \mathrm{~mm}
\end{aligned}
$$

Ukuran belt yang tersedia secara komersial dan mendekati hasil perhitungan adalah belt dengan ukuran $3099 \mathrm{~mm}$, sehingga jarak antar poros disesuaikan kembali. Penyesuaian dilakukan dengan perhitungan yang sama sebagai berikut.

$$
\begin{aligned}
& \mathrm{L}=2 \mathrm{C}+\frac{\pi}{2}\left(\mathrm{~d}_{\mathrm{p}}+\mathrm{D}_{\mathrm{p}}\right)+\frac{1}{4 C}\left(\mathrm{~d}_{\mathrm{p}}+\mathrm{D}_{\mathrm{p}}\right) \\
& 3099=2 . \mathrm{C}+\frac{3,14}{2}(149+750)+\frac{1}{4 .(800)}(149+750) \\
& 3099=2 . \mathrm{C}+1411,43+0,28 \\
& 3099-1411,43-0,28=2 \mathrm{C} \\
& 1687,29=2 \mathrm{C} \\
& \mathrm{C}=1687,29 / 2=843,645 \mathrm{~mm} \approx 844 \mathrm{~mm}
\end{aligned}
$$

Skema pulley dan belt pada PLTMH Banjar Dinas Mekar Sari ditunjukkan pada Gambar 6.

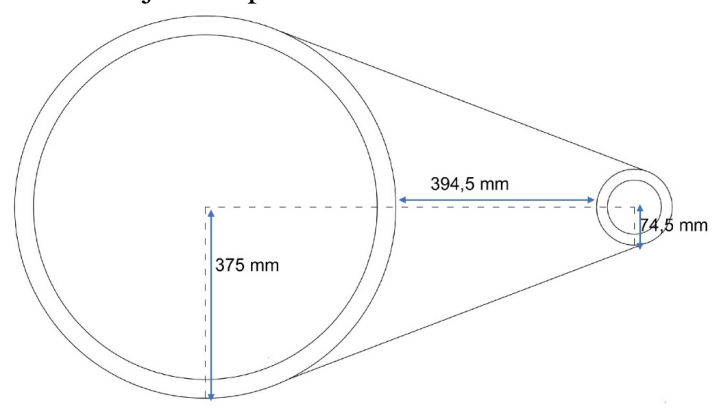

Gambar 6: Skema Pulley dan Belt PLTMH Banjar Dinas Mekar Sari

\section{Sistem Kontrol Daya}

Sistem kontrol yang digunakan pada perencanaan sistem kelistrikan PLTMH Banjar Dinas Mekar Sari adalah Electronic Load Controller (ELC) karena output daya PLTMH lebih besar dari $5 \mathrm{~kW}$. ELC juga digunakan karena

I P. E. April Yanto: Perencanaan Sistem Kelistrikan Pembangkit ... memiliki respon yang cepat terhadap perubahan beban serta tidak memerlukan governor.

ELC pada PLTMH Banjar Dinas Mekar Sari dilengkapi dengan ballast load. Kapasitas ballast load yang digunakan akan disesuaikan dengan kapasitas daya generator. Hal ini bertujuan apabila sistem tidak dapat terhubung ke jaringan PLN maka daya dapat disalurkan menuju ballast load sebelum PLTMH berhenti dioperasikan [22].

Nilai faktor daya pada ballast load adalah 1 , nilai ini berdasarkan pada komponen ballast load yang berupa pemanas air dengan sifat resistif. Berdasarkan hal tersebut maka kapasitas ballast load yang diperlukan adalah sebesar $185 \mathrm{~kW}$, atau $61,6 \mathrm{~kW}$ pada masing-masing fasa agar dapat sebanding dengan kapasitas generator. Berdasarkan hasil survei komponen yang mendekati hasil perhitungan, variasi ballast load yang digunakan adalah 2 buah water heater dengan kapasitas $30 \mathrm{~kW}$ pada masing-masing fasa agar pengontrolan dapat dilakukan melalui dua tahap. Meskipun kapasitas ballast load terdapat perbedaan sebesar $5 \mathrm{~kW}$, perbedaan tersebut tidak terlalu besar pengaruhnya terhadap sistem PLTMH karena daya output yang dihasilkan PLTMH hanya sebesar 165,44 kW. Skema ELC-ballast load ditunjukkan pada Gambar 7.

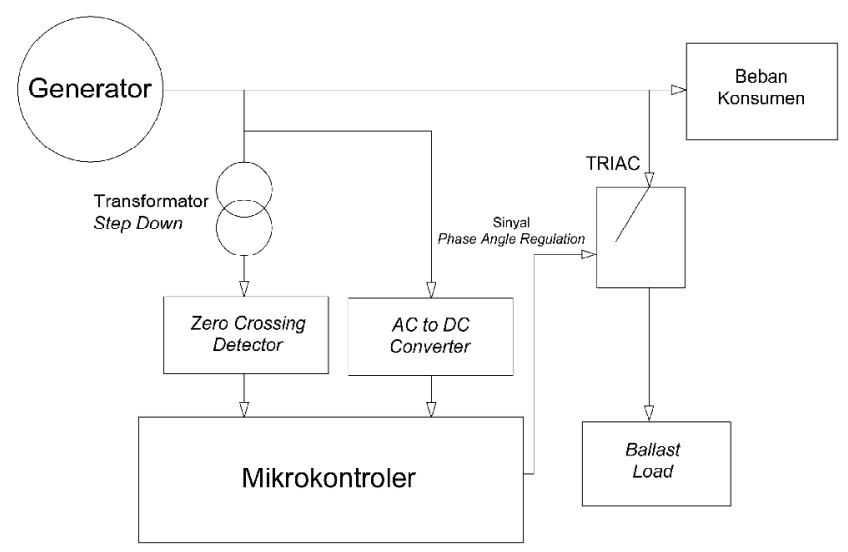

Gambar 7: Skema ELC-ballast load

\section{E. Sistem Sinkronisasi}

Sistem sinkronisasi merupakan pengontrol sekaligus protektor pembangkit untuk sistem interkoneksi dengan grid. Sistem sinkronisasi berfungsi untuk mensinkronkan frekuensi, tegangan, dan urutan fasa pembangkit dengan grid. Apabila frekuensi, tegangan dan urutan fasa sudah sama maka secara otomatis modul akan menghubungkan daya dari pembangkit ke jaringan. 


\section{F. Pemakaian Sendiri}

PLTMH Banjar Dinas Mekar Sari memerlukan daya listrik untuk kebutuhan operasional. Keperluan kelistrikan pada PLTMH Banjar Dinas Mekar Sari yaitu berupa penerangan pada rumah daya dan beberapa kotak kontak untuk keperluan pemeliharaan yang dirincikan sebagai berikut :

\section{1) Titik Lampu pada Rumah Daya}

Jumlah titik lampu dihitung berdasarkan ukuran dan peruntukan ruangan yang akan digunakan. Ukuran rumah daya sebuah PLTMH disesuaikan agar komponen PLTMH baik turbin, generator maupun sistem kontrol dapat terakomodasi di dalamnya. Ukuran rumah daya yang digunakan pada PLTMH Banjar Dinas Mekar Sari diasumsikan berukuran panjang $4 \mathrm{~m}$, lebar $3 \mathrm{~m}$ dan tinggi $4 \mathrm{~m}$. Berdasarkan pada jenis pekerjaan yang dilakukan pada PLTMH yang meliputi pengawasan dan pemeliharaan mekanikal-elektrikal maka intensitas penerangan yang dibutuhkan sebesar 500 lux [23]. Dengan asumsi pengotoran sedang maka nilai faktor depresiasi adalah 0,8 dan efisiensi penerangan 0,42 [23]. Lampu yang akan digunakan adalah Lampu TL $2 \times 36 \mathrm{~W}, 6700$ lumen. Sehingga jumlah titik lampu yang dipasang adalah :

$$
n=\frac{500 \times 12}{6700 \times 0.42 \times 0.8}=2,6 \approx 3
$$

Berdasarkan perhitungan tersebut, jumlah lampu yang digunakan pada rumah daya adalah 3 buah TL $2 \times 36 \mathrm{~W}$ dengan total daya $216 \mathrm{~W}$. Kabel yang digunakan untuk instalasi lampu adalah NYY $2 \times 1,5 \mathrm{~mm}^{2}$. Selain penerangan pada rumah daya, penerangan di sekitarnya juga diperlukan, sehingga digunakan 2 buah lampu $24 \mathrm{~W}$ sebagai penerangan di halaman rumah daya.

\section{2) Keperluan Kotak Kontak untuk Peralatan Pemeliharaan} Asumsi peralatan pemeliharaan yang akan digunakan pada PLTMH Banjar Dinas Mekar Sari ditunjukkan pada Tabel 2. TABEL II

ASUMSI PERALATAN PEMELIHARAAN

\begin{tabular}{ccc}
\hline No & Peralatan & Daya \\
\hline $\mathbf{1}$ & Bor Listrik & 450 Watt \\
\hline $\mathbf{2}$ & Mesin Las & 450 Watt \\
\hline $\mathbf{3}$ & Gerinda & 500 Watt \\
\hline & Total & 1400 Watt
\end{tabular}

Dengan asumsi bahwa peralatan untuk pemeliharaan tidak digunakan secara bersamaan maka dipasang kotak kontak sebanyak 2 buah. Kabel yang digunakan pada instalasi kotak kontak adalah NYY $3 \times 2,5 \mathrm{~mm}^{2}$.

Berdasarkan total keperluan daya yang dibutuhkan PLTMH Banjar Dinas Mekar Sari untuk pemakaian sendiri maka ditetapkan besaran daya yang digunakan adalah sebesar 1300 VA. Saat PLTMH beroperasi, kebutuhan daya tersebut diperoleh dari output daya PLTMH. Sedangkan apabila PLTMH tidak beroperasi, maka daya akan diperoleh dari PLN dan terhitung pada kWH Exim.

\section{G. kWh Meter}

kWh meter digunakan untuk mengukur daya yang disalurkan PLTMH Banjar Dinas Mekar Sari. kWh Meter 3 fasa - Expor Impor (Exim) digunakan pada PLTMH Banjar Dinas Sari dengan tujuan untuk mengantisipasi apabila terjadi perkembangan kebutuhan kelistrikan pada PLTMH. Perkembangan yang dimaksud adalah pemanfaatan sendiri output PLTMH untuk kepentingan kelompok sehingga tidak diperlukan lagi penggantian komponen kWH meter.

\section{H. Jaringan Tegangan Rendah}

Pemilihan konstruksi JTR PLTMH Banjar Dinas Mekar Sari yang digunakan diperoleh berdasarkan peninjauan jalur pemasangan JTR. Kondisi jalur lintas JTR PLTMH Banjar Dinas Mekar Sari merupakan perkebunan sehingga tidak dapat memenuhi ruang bebas hambatan jika menggunakan konstruksi Saluran Udara Tegangan Rendah Kabel Pilin atau Saluran Udara Tegangan Rendah Bare Conductor. Berdasarkan kondisi tersebut, maka konstruksi yang digunakan pada JTR PLTMH Banjar Dinas Mekar Sari adalah Saluran Kabel Tanah Tegangan Rendah.

Pemilihan jenis kabel untuk Saluran Kabel Tanah Tegangan Rendah mengacu pada jenis kabel yang digunakan oleh PLN yaitu Low Voltage Cable (LVC) berjenis NYFGbY [15] Sedangkan untuk penentuan ukuran kabel harus mempertimbangkan kemampuan hantar arus (KHA) [16].

Daya yang disalurkan menggunakan kabel adalah sebesar $165,44 \mathrm{kVA}$ atau $165.440 \mathrm{VA}$, sehingga besaran arus yang disalurkan dapat dihitung sebagai berikut.

$$
\begin{aligned}
\mathrm{I}_{\text {saluran }} & =\frac{s}{\sqrt{3} \times V} \\
\mathrm{I}_{\text {saluran }} & =\frac{165.440}{\sqrt{3} \times 400} \\
\mathrm{I}_{\text {saluran }} & =238,79 \mathrm{~A}
\end{aligned}
$$

Berdasarkan besaran arus tersebut, maka ukuran kabel yang digunakan adalah NYFGbY $4 \times 95 \mathrm{~mm}^{2}$. Spesifikasi

\begin{tabular}{|c|c|c|}
\hline No & Indikator & Spesifikasi \\
\hline 1 & Konduktor & Tembaga \\
\hline 2 & Isolasi & $\begin{array}{c}\text { PVC, Armor Datar Baja } \\
\text { Galvanis, Berselubung PVC }\end{array}$ \\
\hline 3 & Diameter Keseluruhan & $44,7 \mathrm{~mm}$ \\
\hline 4 & Berat Keseluruhan & $5,186 \mathrm{~kg} / \mathrm{km}$ \\
\hline 5 & $\begin{array}{l}\text { Resistansi Maksimal (AC) } \\
\text { Pada Suhu } 70^{\circ} \mathrm{C}\end{array}$ & $0.238 \mathrm{ohm} / \mathrm{km}$ \\
\hline 6 & $\begin{array}{l}\text { Tahanan Isolasi Minimal } \\
\text { Pada Suhu } 20^{\circ} \mathrm{C}\end{array}$ & 30 M.ohm.km \\
\hline 7 & Induktansi & $0,233 \mathrm{mH} / \mathrm{km}$ \\
\hline 8 & $\begin{array}{l}\text { Kemampuan Hantar Arus } \\
\text { Maksimal Pada Suhu } 30^{\circ} \mathrm{C}\end{array}$ & $\begin{array}{l}245 \text { A (di udara) dan } 250 \text { A (di } \\
\text { tanah) }\end{array}$ \\
\hline 9 & $\begin{array}{c}\text { Arus Hubung Singkat } \\
\text { Maksimal Pada Rentang } 1 \\
\text { Detik }\end{array}$ & $11.05 \mathrm{kA}$ \\
\hline
\end{tabular}
kabel NYFGbY $4 \times 95 \mathrm{~mm}^{2}$ ditunjukkan pada Tabel 3 .

TABEL III

SPESIFIKASI STANDAR NYFGBY $4 \times 95 \mathrm{MM}^{2}$ [24]

Penentuan panjang kabel yang digunakan berdasarkan pada panjang garis elevasi. Garis elevasi dihitung berdasarkan panjang garis horizontal dan selisih TPL titik akhir dengan titik awal. Perhitungan menggunakan persamaan phytagoras. Berdasarkan hasil perhitungan didapatkan bahwa panjang jalur JTR adalah sepanjang $69 \mathrm{~m}$. Gambar jalur JTR ditunjukkan pada Gambar 8. 


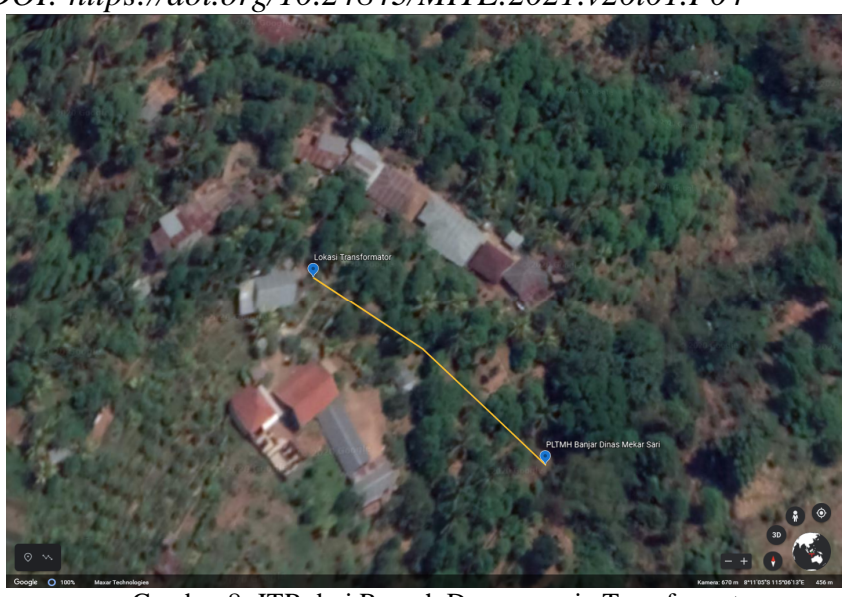

Gambar 8: JTR dari Rumah Daya menuju Transformator

Berdasarkan panjang lintas JTR maka dapat dihitung kebutuhan pasir urug dan beton peringatan yang digunakan. Jumlah pasir urug yang digunakan berdasarkan pada perhitungan volume pasir dengan tebal $20 \mathrm{~cm}$ dan lebar $40 \mathrm{~cm}$ sepanjang $69 \mathrm{~m}$. Berdasarkan perhitungan tersebut, didapatkan bahwa volume pasir urug yang dibutuhkan adalah sebesar $5,52 \mathrm{~m}^{3}$. Beton peringatan yang digunakan yaitu Beton Cover$U$ Ditch 40 dengan lebar $40 \mathrm{~cm}$, panjang $60 \mathrm{~cm}$, dan tebal 6 $\mathrm{cm}$. Jumlah beton peringatan yang digunakan dihitung dengan cara membagi panjang jalur JTR dengan panjang Beton Cover- $U$ Ditch 40. Berdasarkan perhitungan tersebut, maka dibutuhkan 115 buah Beton Cover-U Ditch 40.

\section{Transformator}

Transformator Step-Up/Step-Down berfungsi untuk menaikkan tegangan dari pembangkit untuk disalurkan menuju jaringan $20 \mathrm{kV}$ PLN, begitu juga sebaliknya. Kapasitas transformator yang digunakan berdasarkan pada kapasitas generator PLTMH yaitu sebesar 185 kVA. Dengan mempertimbangkan faktor keamanan rating pembebanan transformator sebesar $80 \%$ maka kapasitas transformator yang digunakan dapat dihitung sebagai berikut:

$$
\begin{aligned}
& \mathrm{S}_{\text {trafo }}=\frac{P(k V A)}{0,8} \\
& \mathrm{~S}_{\text {trafo }}=\frac{185 \mathrm{kVA}}{0,8} \\
& \mathrm{~S}_{\text {trafo }}=231,25 \mathrm{kVA}
\end{aligned}
$$

Berdasarkan hasil survei, transformator yang mendekati hasil perhitungan adalah transformator dengan kapasitas 250 kVA. Energi listrik yang telah dinaikkan tegangannya kemudian disalurkan ke JTM 20 kV Penyulang Panji yang berjarak 700 meter dari lokasi transformator.

\section{J. Skema Rancangan}

Secara keseluruhan, hasil rancangan sistem kelistrikan PLTMH di Banjar Mekar Sari dapat digambarkan dalam skema dan diagram seperti ditunjukkan pada Gambar 9 sampai dengan Gambar 11. Gambar 9 menunjukkan diagram segaris instalasi listrik pemakaian sendiri PLTMH Banjar Dinas Mekar Sari, sedangkan Gambar 10 menunjukkan diagram sederhana perencanaan sistem kelistrikan PLTMH Banjar Dinas Mekar Sari. Gambar 11 menunjukkan diagram segaris titik penyambungan PLTMH pada Penyulang Panji.

\section{KESIMPULAN}

Berdasarkan hasil rancangan sistem kelistrikan PLTMH Banjar Dinas Mekar Sari, didapatkan kesimpulan bahwa daya listrik yang dibangkitkan PLTMH adalah sebesar 165,44 kVA. Generator yang digunakan berkapasitas 185 kVA dengan efisiensi 94\%. Electronic Load Controller yang digunakan berkapasitas $180 \mathrm{~kW}$, dengan 6 buah ballast load $30 \mathrm{~kW}$. Sambungan dari generator ke transformator menggunakan kabel bawah tanah NYFGbY $4 \times 95 \mathrm{~mm}^{2}$, dengan panjang 69 $\mathrm{m}$. Transformator yang digunakan berjenis step-up/step-down dengan kapasitas $250 \mathrm{kVA}$. Energi listrik yang dihasilkan PLTMH disalurkan pada jaringan tegangan menengah Penyulang Panji dengan titik sambung di SK064.

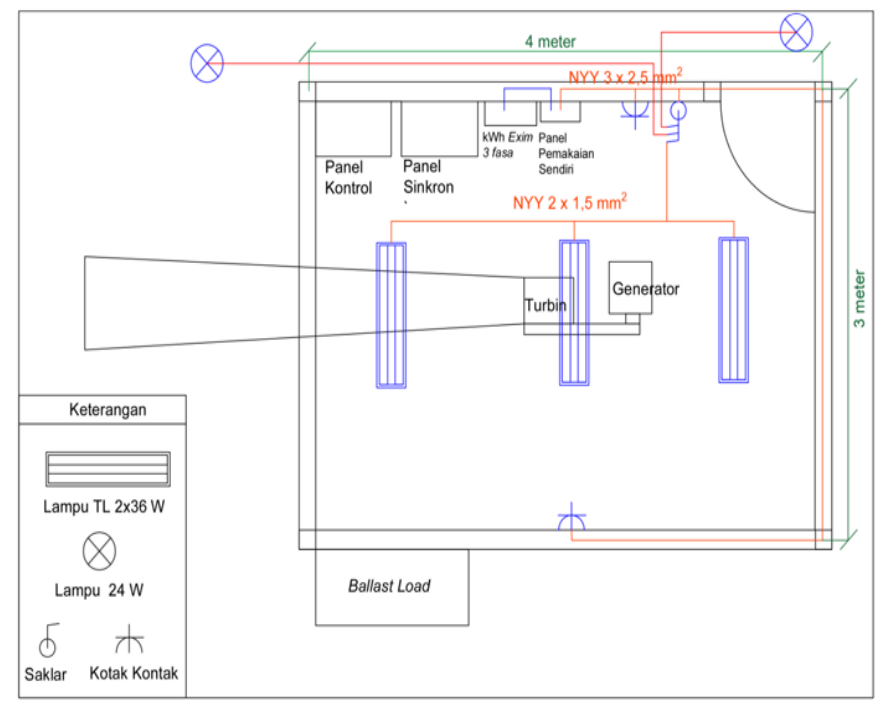

Gambar 9: Diagram Segaris Instalasi Listrik Pemakaian Sendiri PLTMH Banjar Dinas Mekar Sari 


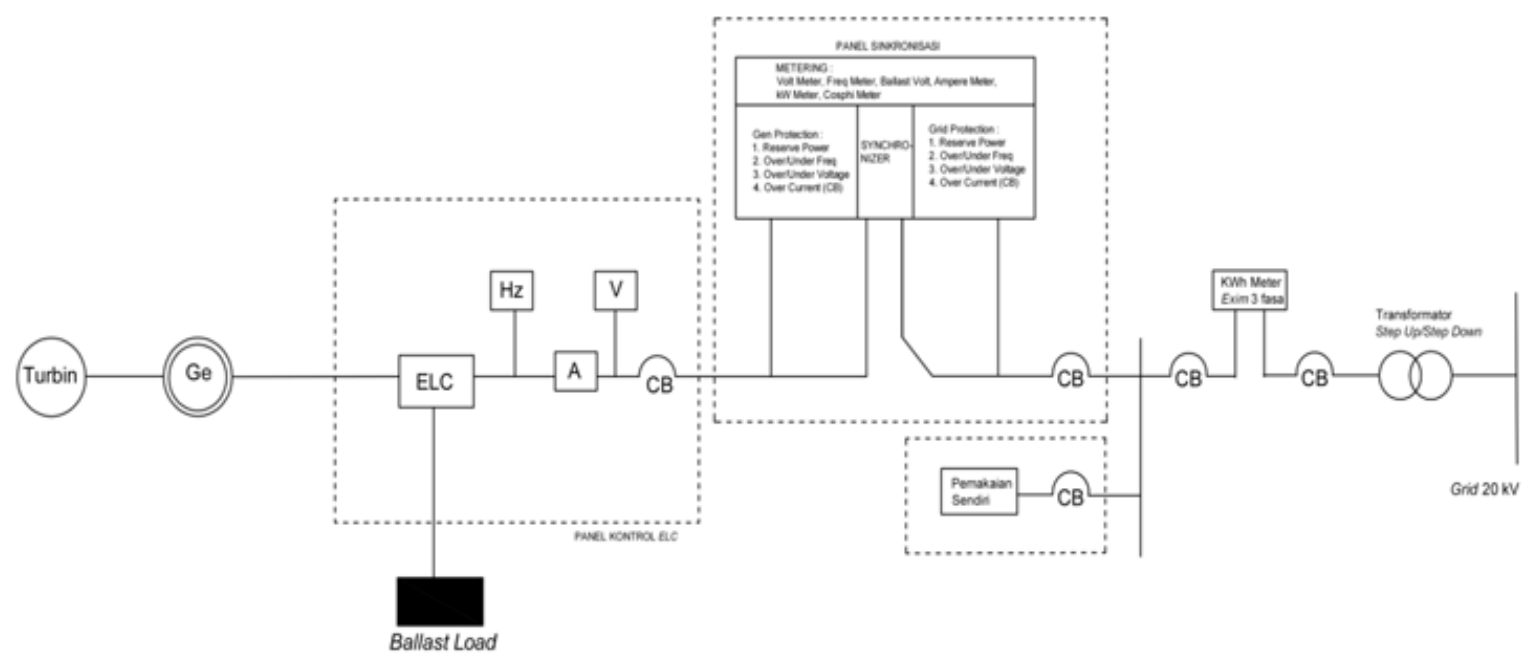

Gambar 10: Diagram Segaris Perencanaan Sistem Kelistrikan PLTMH Banjar Dinas Mekar Sari

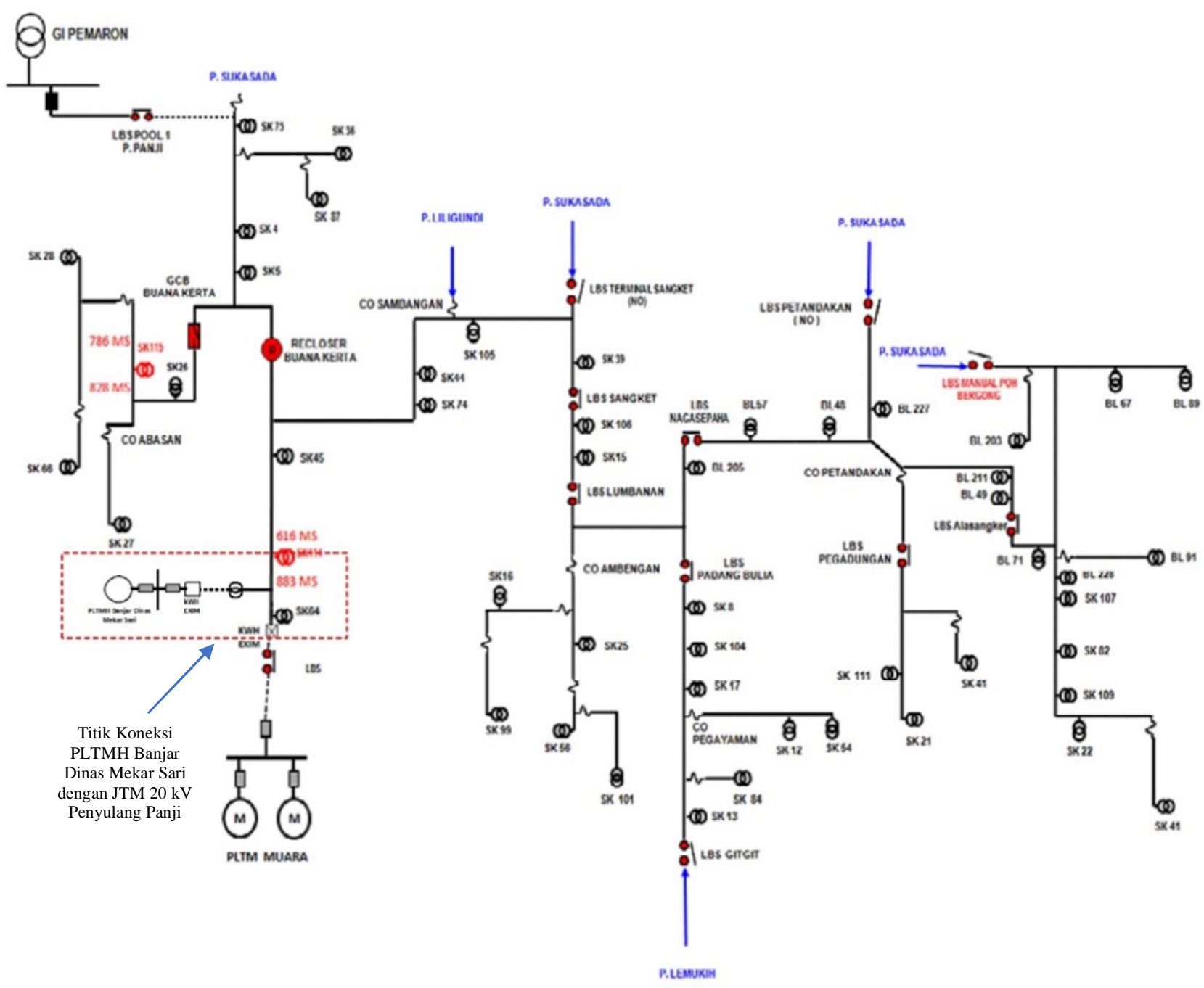

Gambar 11: Diagram Segaris Penyulang Panji [25] 


\section{REFERENSI}

[1] Vries, P.d, dkk. 2010. Buku Panduan Energi yang Terbarukan. Jakarta: Kementerian Dalam Negeri.

[2] PT PLN (Persero). 2019. Rencana Usaha Penyediaan Tenaga Listrik (RUPTL) Tahun 2019-2028. Jakarta: PT PLN (Persero).

[3] Sari, P. D. dan Kumara, I. N. S. 2018. The Development of Jatiluwih Micro-Hydro Power Plants To Support Tourism Destinations. ISCECE. 9-14.

[4] Suparyawan, D.P.D, Kumara, I.N.S, Ariastina, W.G. 2013. Stud Perencanaan Pembangkit Listrik Tenaga Mikrohidro di Desa Sambangan Kabupaten Buleleng Bali. Majalah Ilmiah Teknologi Elektro. 12(2): 1-8.

[5] Kumara, D. P. D. Suparyawan, W. G. Ariastina, W. Sukerayasa and I A. D. Giriantari, "Microhydro powerplant for rural area in Bali to generate green and sustainable electricity," 2014 International Conference on Smart Green Technology in Electrical and Information Systems (ICSGTEIS), Kuta, 2014, pp. 113-117, doi: 10.1109/ICSGTEIS.2014.7038741.

[6] Gunawan, A., Oktafeni, A., Khabzali, W. 2013. Pemantauan Pembangkit Listrik Tenaga Mikrohidro (PLTMH). Jurnal rekayasa elektrika. 10 (4): 20

[7] Sugiyono, A. 2009. Pemberdayaan Masyarakat dalam Mengelola Potensi Sumber Daya Air melalui Pengembangan Pembangkit Listrik Tenaga Mini/Mikro Hidro. JESP. 1(3): 121-128.

[8] Kjølle, A. 2001. Hydropower in Norway, Mechanical Equipment. Trondheim: Norwegian University of Science and Technology.

[9] Arismunandar, A. 1991. Buku Pegangan Teknik Tenaga Listrik I. Jakarta: PT. Pradnya Paramita.

[10] Kurniawan, A dkk. 2009. Pedoman Studi Kelayakan Mekanikal Elektrikal. Jakarta: Dirjen ESDM.

[11] Prayuda, D.A. 2014. "Perencanaan Transmisi Sabuk V dan Pulley Pada Pembangkit Listrik Tenaga Mikrohidro" (skripsi). Jember: Universitas Jember.

[12] Saragih, A.M.S. 2017. "Studi Pemodelan Electronic Load Controller sebagai Alat Pengatur Beban Pembangkit Listrik Tenaga Mikro-Hidro" (skripsi). Bandung: Institut Teknologi Bandung.

[13] Slamet. 2012. Pengendali Beban Elektronik Tiga Fasa Menggunakan Mikro Kontroler Pada Pembangkit Listrik Mikro Hidro (PLTMH). Ketenagalistrikan Dan Energi Terbarukan. 11(1): 67-80.

[14] Partha, C. G. I. 2014. Dasar Instalasi Listrik. Denpasar: Universitas Udayana.

[15] PT. PLN (Persero). 2010. Standar Konstruksi Jaringan Tegangan Rendah Tenaga Listrik. Jakarta: PT. PLN Persero

[16] Kusdiana, D dkk. 2008. Pedoman Teknis Standarisasi Peralatan dan Komponen Pembangkit Listrik Tenaga Mikrohidro (PLTMH). Jakarta: Dirjen ESDM.

[17] Pabla, A.S. dan Hadi, A. 1994. Sistem Distribusi Daya Listrik. Jakarta: Erlangga.

[18] Sampeallo, A., S. 2012. Penentuan Kapasitas Transformator Daya Pada Perencanaan Gardu Induk (GI) Sistem 70 kV (Studi Kasus Pembangunan Gardu Induk Ende - Ropa - Maumere). Seminar Nasional Sains dan Teknik 2012 (SAINSTEK 2012)

[19] BPS Kab Buleleng. 2017. Kecamatan Sukasada dalam Angka 2017. https://bulelengkab.bps.go.id/publication/2017/09/20/547295c3d2d75c d3541434ad/kecamatan-sukasada-dalam-angka-2017.html. Diakses tanggal 9 Juli 2020.

[20] LAKSANA, Dewa Putu Ari; GIRIANTARI, Ida Ayu Dwi; SATYA KUMARA, I Nyoman. Redesain Turbin 175 KW Untuk Pembangkit Listrik Tenaga Mikrohidro (PLTMH) Desa Mekar Sari Buleleng Bali. Majalah Ilmiah Teknologi Elektro, [S.1.], v. 19, n. 2, p. 241-248.

I P. E. April Yanto: Perencanaan Sistem Kelistrikan Pembangkit ...
[21] Nugroho, D., Suprajitno, A., Gunawan. 2017. Desain Pembangkit Listrik Tenaga Mikrohidro di Air Terjun Kedung Kayang. Jurnal Rekayasa Elektrika. 13(3): 161-171.

[22] Asri. 2014. Kapasitas Daya Pembangkit Listrik Tenaga Mikrohidro di Alue Dua Aceh Utara. Jurnal Rekayasa Elektrika. 11(2): 54-61.

[23] Harten, P.V. dan Setiawan, Ir. E. 1986. Instalasi Listrik Arus Kuat 2. Jakarta: Bina Cipta Bandung.

[24] PT. Sutrakabel Intimandiri. 2010. Sutrado Kabel Product Catalogue. Bogor: PT. Sutrakabel Intimandiri.

[25] PT. PLN (Persero) Distribusi Bali Area Bali Utara. 2019. Single Line Diagram Penyulang Panji. Buleleng: PT. PLN (Persero). 
\{ Halaman ini sengaja dikosongkan \} 